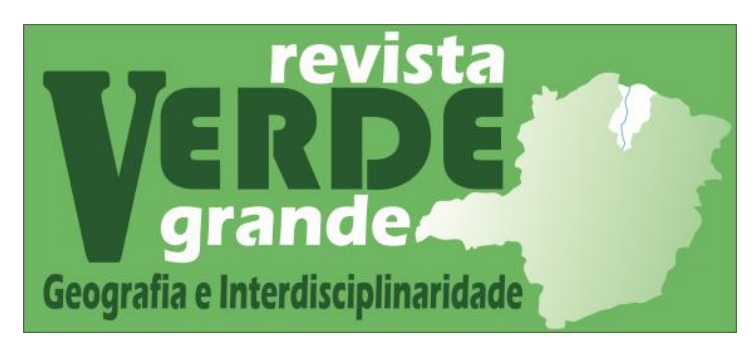

Volume 2, no. 2 (2020)

ISSN: 2675-2395

https://doi.org/10.46551/rvg267523952020290104

\title{
APRENDIZAGEM SIGNIFICATIVA E A INTELIGÊNCIA ESPACIAL: UMA POSSIBILIDADE DE ATUAÇÃO NA CARTOGRAFIA ESCOLAR
}

Meaningful Learning and the Spatial Intelligence: a possibility of performance in school cartography

Giovana Oliveira do Nascimento ${ }^{1}$ https://orcid.org/0000-0001-8700-2276

Anderson de Almeida Morato ${ }^{2}$ https://orcid.org/0000-0002-4882-1399

\footnotetext{
${ }^{1}$ Mestranda PPG/GEOPROF - Universidade Federal do Rio Grande do Norte - UFRN. E-mail: giovana.oliveira804@gmail.com

${ }^{2}$ Licenciado em Geografia - Instituto Federal de Educação, Ciência e Tecnologia do Rio Grande do Norte - IFRN. E-mail: andersonmorato68@gmail.com
}

\begin{abstract}
Resumo
O presente trabalho constitui-se de uma revisão bibliográfica da correlação entre a teoria das múltiplas inteligências, elaborada por Howard Gardner, e a teoria da aprendizagem significativa, proposta por David Ausubel, em uma atuação conjunta entre elas no ensino da cartografia escolar. Partindo da compreensão de que os conteúdos abordados dentro da Geografia Escolar seguem uma evolução teórica conceitual, bem como cognitiva, sendo o ensino sequencial e basilar para os demais anos da vida escolar. Portanto, inicialmente, o estudo aborda a importância da cartografia para a Ciência Geográfica, até sua evolução e reconstrução no ensino, mediante uma cartografia escolar. A posteriori, relacionando esta linguagem com a perspectiva de Gardner sob a inteligência espacial, tendo em vista que a Geografia explora a espacialidade dos fenômenos, conectando os estudos de Ausubel sobre a aprendizagem significativa. Consequentemente, o professor de geografia poderá apropriar-se dos elementos teóricos e metodológicos a sua práxis no ensino da cartografia escolar, por intermédio de uma linguagem espacial dos conteúdos relevantes e significativos para os alunos.
\end{abstract}

Palavras-chave: Aprendizagem significativa. Inteligências Múltiplas. Cartografia Escolar.

\begin{abstract}
The present study consists in a literature review of the correlation between the Howard Gardner's theory of Multiple Intelligences and the Meaningful Learning theory, by David Ausubel, in a conjunct action between them in the teaching of school cartography. Starting from the understanding that the contents covered in school Geography follow a conceptual theoretical evolution, as well as cognitive, being the sequential and basic teaching for the other years of school life. Thus, the teaching seeks initially addresses the importance of cartography to geographical science until its evolution and reconstruction on teaching, through the school cartography, later relating this language whit the Gardner's perspective about spatial intelligence, given that Geography explores the spatiality of phenomena and then connect the Ausubel's studies about meaningful learning, where the geography teacher can appropriate theoretical and methodological elements to his praxis searching teach through cartography and a spatial language, contents whit relevance and significance to students.
\end{abstract}

Keywords: Meaningful Learning. Multiple Intelligences. School Cartography. 


\section{Introdução}

Na educação básica, os primeiros anos escolares são essenciais para a construção das bases do conhecimento nas diversas disciplinas, sendo aporte para compreensão de conceitos, definições, formas de observar o mundo e características de um determinado saber. Tais bases, servem posteriormente como adjuntos de ideias e estruturas complexas ao longo da vida escolar dos alunos.

No Ensino de Geografia esse princípio não se difere, a valer é extremamente marcante no tocante evolutivo da educação geográfica, visto que é executada na perspectiva evolutiva dos conteúdos, que se repetem em graus de desafios cognitivos diferenciados. Dentro da Geografia Escolar, uma abordagem se faz predominante em todas as séries e conteúdos: a leitura do mundo, partindo de um olhar geográfico levando a possibilidade do aluno a refletir sobre o mundo que o cerca.

Nessa perspectiva, a cartografia recebe um destaque especial a leitura do mundo, pois foi através da linguagem cartográfica que a Geografia se consolidou enquanto ciência de observação do mundo, no reconhecimento dos espaços, na descrição das paisagens e na narrativa dos lugares. E essa mesma abordagem cartográfica presente na Ciência, retorna ao ensino como ferramenta e recurso didático que possibilita ao aluno perceber o espaço geográfico, de forma escalar, e no entendimento dos fenômenos geográficos por meio de uma espacialização do lugar.

O uso da Cartografia, enquanto linguagem na sala de aula, está atrelado diretamente com o desenvolvimento da habilidade e competência espacial dos alunos, em perceber formas, abstrair imagens, observar detalhes gráficos, permitindo-os um raciocínio espacial.

Em vista disso, levando em consideração tal abordagem espacial no Ensino de Geografia por meio da cartografia escolar, o presente trabalho objetiva-se em relacionar duas teorias de bases educativas. Em consequencia de uma revisão bibliográfica, que aponte às possibilidades que ambas às teorias possuem para favorecer um aprendizado significativo. Dentre às teorias a serem exploradas, está os estudos elaborados pelo psicólogo e professor Howard Gardner, que aborda a teoria das múltiplas inteligências. Ele prevê oito tipos distintos de inteligências presentes nos indivíduos, passíveis a estímulos de desenvolvimento, por qual essa análise pretende focar na inteligência espacial, enquanto categoria presente a Geografia.

Bem como também, pretende-se abordar a teoria da aprendizagem significativa, elaborada pelo psicólogo David Ausubel, que a desenvolveu com base nos conhecimentos 
prévios que o estudante possui sobre determinado tema antes da apresentação da aula. $\mathrm{O}$ professor atuando na perspectiva da aprendizagem significativa, buscará utilizar técnicas e estratégias que façam com que o tema seja significativo para o aluno.

Valadares e Moreira (2009, p. 12) discutem a teoria afirmando que "o conhecimento não é um facto absoluto e imutável, é um processo em construção envolvendo visões, conceitos, modelos, teorias e metodologias com que o sujeito encara o mundo, mas nem o sujeito e objeto de conhecimento têm uma hegemonia epistemológica.". Os autores apontam que o conhecimento está em constante transformação e, nem o sujeito ou o conhecimento possuem formas fixas que não possam se modificar.

Essa parte da necessidade de explorar campos para um ensino significativo ao aluno, o qual ele se reconhece como autor principal no processo de aprendizagem, e pelo qual o conteúdo jamais deve distanciar-se, em que a Geografia Escolar é ponto chave para essa ligação. Em virtude que seu princípio está no reconhecimento do sujeito no mundo e na apreensão, transformação e construção do mundo pelo sujeito. E de semelhante modo, relacionar ao uso da linguagem cartográfica, por meio do reconhecimento espacial de formação e construção dos mapas, bem como na apreensão dos fenômenos espacializados, no desenvolvimento de uma inteligência espacial do aluno, para com seu meio de vivência.

\section{Princípios da Cartografia na Educação Geográfica}

A cartografia sempre se fez presente enquanto instrumento de localização e orientação, permitindo ao homem a capacidade de traçar caminhos e representar características específicas dos lugares. Desde os primórdios das civilizações humanas, o desenho, enquanto primeiro elemento de comunicação, trazia através da linguagem gráfica, mesmo que de forma elementar, a capacidade de explicar e arquivar informações.

Claval (2014) traz uma abordagem epistemológica da Geografia, presente entre os mais variados povos e sociedades, através de uma geografia vernacular dos saberes-fazeres, que consiste na capacidade de orientação, localização, e descrição dos lugares. O saber-fazer parte de procedimentos simples e conhecimentos para a vida diária, apontando duas vertentes do conhecimento do meio, o domínio da orientação e o conhecimento dos recursos oferecidos, na necessidade de explorar a ecologia dos lugares.

Dentro da evolução humana e social, o saber-fazer e as geografias vernaculares, criaram subsídios para o surgimento de uma Geografia Científica, desenvolvida como uma Ciência da observação e da análise. Sua marca está na "Utilização de um sistema de coordenadas 
universalmente válido", Claval (2014, p.55) ainda enfatiza que a diferença entre a Geografia e as outras disciplinas científicas está no destaque que dá a localização dos dados.

A cartografia dos dados geográficos destaca distribuições espaciais mais ou menos estruturadas. [...] O conjunto e informações localizadas constitui a base sobre a qual se preparam as decisões que têm a ver com o espaço e a partir da qual se elaboram os saberes geográficos (CLAVAL, 2014, p. 76-77).

Presentemente, a Cartografia constitui-se como elemento chave da Geografia Científica, sua preocupação está na localização, espacialização e representação dos fenômenos geográficos. Ela é narrativa e descritiva, e em sua essência traz dados e informações capazes materializar espaços geográficos. O mapa, portanto, irá se constituir como o recurso material dessas representações.

[...] mapa é definido como uma representação simbolizada da realidade geográfica, representando feições ou características selecionadas, resultante do esforço criativo da execução de escolhas de seu autor, tendo sido concebido para uso quando as relações espaciais são de relevância primordial (MENEGUETTE, 2012, p.7).

Segundo Gomes (2017, p. 36), o mapa enquanto "quadro" será instrumento do pensamento geográfico, possibilitando uma pluralidade de análises e observações sobre os aspectos que o compõe, de modo que conduz à localização e a diversidade de elementos expostos em sua escala. Portanto, a base da ação de pensar geograficamente está consolidada no mapa, compreendido como imagem-padrão para representação dos fenômenos geográficos (IDEM).

Essa própria linguagem cartográfica, presente em uma Geografia Científica, é decisiva ao ensino de Geografia na passagem do saber científico ao conhecimento escolar, que faz uso dos princípios desenvolvidos pela ciência, enquanto conhecimento e princípio formativo. Logo, o mapa sempre foi utilizado pelo geógrafo como modelo e representação da terra, bem como no ensino de Geografia enquanto documento e recurso na sala de aula (ALMEIDA, 2010, p.17).

Em uma perspectiva do ensino, a linguagem cartográfica sempre foi utilizada pelas mais diversas disciplinas como elemento didático de representação dos lugares, todavia o ensino de Geografia ganha destaque perante esse uso, por ter a habilidade de criar e estruturar um pensamento a partir da leitura dos mapas. Aplicado ao ensino, o mapa é definido por Almeida (2010, p.19) enquanto "um recurso visual a que o professor deve recorrer para ensinar Geografia e que o aluno deve manipular para aprender os fenômenos geográficos". 
FIGURA 1: Bases da Cartografia

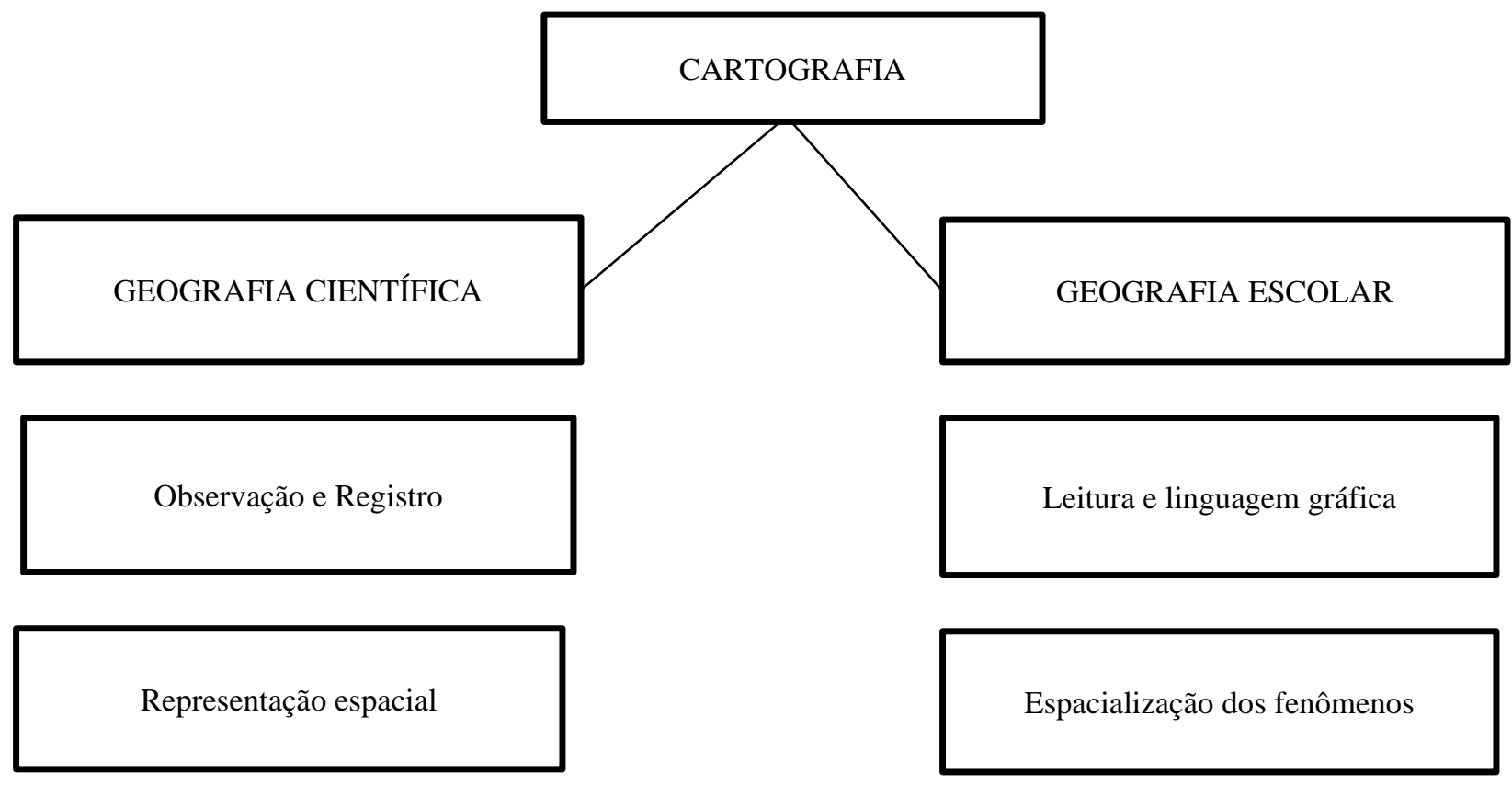

Fonte: autor (2019).

A figura (fig. 1) representa a relação existente entre os princípios da Cartografia, permeando pelos campos de uma Geografia Científica e uma Geografia Escolar, outrora explorados, de forma que ambos se relacionavam na construção, percepção e ensino, visando o reconhecimento do espaço e lugar.

\section{Alfabetização Cartográfica E O Uso Dos Mapas No Ensino De Geografia}

Apontando o desenvolvimento da interpretação e leitura do mundo, a partir da Geografia, Schäffer et al. (2011, p.19) enfatiza a necessidade de uma alfabetização na leitura dos lugares, sejam eles próximos ou distantes, pelo qual perpassa "pelo uso de globos e mapas". Essa se preocupa com o conhecimento dos lugares e na compreensão dos "porquês de objetos e de grupos sociais estarem neste ou naquele lugar”. A utilização de instrumentos de localização tal qual o mapa, traz ao ensino a potencialidade de materializar conteúdos, promovendo uma experiência empírica de interpretação ao aluno.

Há uma necessidade da promoção da alfabetização cartográfica ao aluno do ensino básico, dentro da abordagem cartográfica no Ensino de Geografia, na intenção formativa de alunos capazes de captar e interpretar instrumentos cartográficos. A fim de desenvolver noções de espacialidade em uma abordagem escalar dos estudos geográficos. A alfabetização cartográfica é um elemento essencial a instrução escolar, tendo como objetivo o 
desenvolvimento de competências, a partir de representação no entendimento das dinâmicas espaciais (SANTOS; FECHINE, 2017, p.502).

As interações com os espaços de vivência aos poucos proporcionam as crianças a percepção das complexidades existentes no espaço geográfico, e em sua formação é fundamental que sejam capazes de realizar leituras do mundo construído, do espaço social, físico e cultural, utilizando a linguagem cartográfica, onde o processo de alfabetização não deve ser secundário, mas significativo na compreensão do mundo (LUDWING; MARTINS, 2019).

Aprender a pensar o espaço, para isso, é necessário aprender a ler o espaço, “que significa criar condições para que a criança leia o espaço vivido" (CASTELAR, 2000, p. 30). Fazer essa leitura demanda uma série de condições, que podem ser resumidas na necessidade de se realizar uma alfabetização cartográfica, e esse "é um processo que se inicia quando a criança reconhece os lugares, conseguindo identificar as paisagens" (idem, ibid.). Para tanto, ela precisa saber olhar, observar, descrever, registrar e analisar.

Nascimento e Ludwig (2015, p.30) afirmam que a linguagem cartográfica e suas produções materiais, tal qual mapas, plantas, globos, croquis, dentre outros, contribuem para o aprendizado de forma que possibilite a visualização, análise e interpretação em diferentes escalas e recortes do espaço geográfico.

Uma metodologia do mapa não pode se prender unicamente ao processo perceptivo; também é preciso compreender e explicar o processo representativo, ou seja, é necessário que o mapa, que é uma representação espacial, seja abordado de um ângulo que se permita explicar a percepção e apresentação de uma realidade geográfica como parte de um conjunto, que é o próprio pensamento do sujeito (ALMEIDA, 2010, p.17).

Para além do conhecer e descrever, a alfabetização cartográfica é importante como demonstrado por Almeida. É preciso fornecer ao aluno a capacidade de conseguir pensar o espaço em que este está inserido e como as mudanças no espaço podem afetar o aluno como agente transformador do espaço no seu dia-a-dia.

\section{Inteligências Múltiplas: A Inteligência Espacial No Ensino De Geografia}

A concepção de inteligências múltiplas surgiu em meados da década de 1980, proposta por Howard Gardner, psicólogo, pesquisador e professor em Educação da Universidade de Harvard. Sua teoria nasce como uma crítica aos diversos testes de inteligência, baseados em graus de conhecimento, onde a inteligência seria uma grandeza passível de medição, e cujo foco estava nas competências linguísticas e lógico-matemáticas. 
Gardner (1994, p. 46) definiu a inteligência enquanto uma "competência intelectual humana" a qual se apresenta como "[...] um conjunto de habilidades de resolução de problemas". A inteligência como resultado dessa habilidade, na perspectiva de indivíduos capazes de resolverem problemas e dificuldades, ampliando a potencialidade de elaborar problemas próprios, considerando a relevância que essas habilidades estarão em determinados contextos culturais dos indivíduos.

Gardner baseou sua teoria em muitas idéias diferentes, mas a principal delas sustenta que as pessoas manifestam as mais distintas habilidades. [...] as pessoas possuem capacidades diferentes, das quais se valem para criar algo, resolver problemas e produzir bens sociais e culturais, dentro de seu contexto. (SMOLE, 1999, p. 8-9)

Em sua teoria, Gardner estrutura a existência em oito tipos de inteligências, Smole (1999, p.15) enfatiza que "[...] o fundamental consiste em perceber o caráter múltiplo da inteligência e a possibilidade de vermos suas manifestações como uma teia de relações tecidas". Sendo assim, dentro das oito inteligências propostas, o presente trabalho busca uma abordagem focada na inteligência espacial, todavia sabendo que todas elas são correlacionadas entre si.

A inteligência espacial proposta por Gardner (2010), possui relação direta com a abordagem espacial e cartográfica no Ensino de Geografia. Todavia deve ser levado em consideração, que o fato da Geografia está diretamente relacionado com uma habilidade da espacialidade que ela se constitui um domínio da Ciência, bem como o entendimento de que a inteligência espacial não se dá pelo sistema sensorial, pois não há uma inteligência visual ou auditiva (IDEM).

Considerando as teorias de Gardner, e sua abordagem referente a inteligência espacial, Helena Carvalho (2018, p. 26) irá definir como:

Aptidão para formar, manobrar e operar um modelo mental de um mundo espacial. Denota-se nos indivíduos capazes para esta inteligência uma superior perceção, criação e recriação de imagens, um funcionamento cognitivo predominantemente espacial, uma profunda perceção de detalhes visuais, inclusive mínimos, detendo aptidão para apresentação de ideias por recurso a gráficos, quadros ou imagens.

Dessa forma, a inteligência espacial atrelada ao saber geográfico, manifesta-se ao que Antunes (2009, p.17) reconhece como a “[...] capacidade de se relacionar com o próprio espaço que nos envolve". Partindo da referência geográfica, na percepção e leitura do mundo, a qual a abordagem cartográfica da representação dos lugares, torna-se fundamental ao seu 
desenvolvimento, na percepção do indivíduo sob a representação; na capacidade de observar por perspectivas diferentes; na abstração; bem como na formação de estruturas mentais.

Sobre a inteligência espacial, Gardner (1994, p.135) discutiu a relevância desse termo $\Theta$ enquanto "descritivo visual", que deverá relacionar-se com a observação do indivíduo sobre o mundo que o cerca. A inteligência espacial está interligada com habilidades desenvolvidas e aprimoradas, fundamentada na observação e percepção.

[...] a inteligência espacial acarreta algumas capacidades frouxamente relacionadas: a capacidade de reconhecer exemplos do mesmo elemento; a capacidade de transformar ou reconhecer uma transformação de um elemento em outro; a capacidade de evocar formas mentais e então transformar estas formas; a capacidade de produzir uma representação gráfica de informações espaciais; E similares (GARDNER, 1994, p.137).

O desenvolvimento da inteligência espacial é essencial para a orientação no espaço geográfico, parte da abstração do indivíduo em reconhecer o mundo que o cerca e elaborar pontos de referência, em perceber o espaço de forma tridimensional e o decodificá-lo através da linguagem gráfica, e pelo pensamento visual efetuar transformações e modificações aos aspectos de sua experiência visual (ANTUNES, 2009).

O professor de Geografia, durante suas aulas, em diversos momentos deverá utilizar de mapas, croquis, cartogramas, e outros elementos que possibilitam ao aluno a apreensão dos lugares, no reconhecimento de formas, e no desenvolvimento de sua capacidade de abstração. O uso desses recursos implica a promoção de meios para o aperfeiçoamento de habilidades e competências próprias da inteligência espacial.

Por outro lado, quando tratamos dos processos cognitivos por detrás do ensino de Geografia, procuramos enfatizar o desenvolvimento daquelas habilidades e competências próprias à inteligência espacial. Essas habilidades e competências incluem a capacidade de distinguir formas-objetos, manipular perceptos e interpretar suas relações espaciais em diferentes níveis de domínio das habilidades espaciais (BEZ, 2011, p.64).

Esse domínio das capacidades de criação e transformação de elementos mentalmente, poderá favorecer a aquisição de conhecimentos, e essa aquisição tem a possibilidade de ser potencialmente significativa, como será observado após a abordagem da teoria da aprendizagem significativa.

\section{Teoria De Ausubel}

Para Ausubel, a Aprendizagem Significativa surge como ideias novas que de alguma maneira remetam significado para o aprendiz e se relacionam com os conhecimentos pré 
existentes no individuo. Os saberes anteriores são definidos pelo autor como Subsunçores mais conhecidos como ideias ancoras. E as interações dessas, geram um novo conhecimento, que é o resultado das modificações anteriores, após o acréscimo de novas informações, assim ancorando-se no subconeinte do sujeito. $\mathrm{O}$ autor da teoria a define como sendo

O conhecimento é significativo por definição. É o produto significativo de um processo psicológico cognitivo ("saber") que envolve a interacção entre ideias "logicamente" (culturalmente) significativas, ideias anteriores ("ancoradas") relevantes da estrutura cognitiva particular do aprendiz (ou estrutura dos conhecimentos deste) e o "mecanismo" mental do mesmo para aprender de forma significativa ou para adquirir e reter conhecimentos. AUSUBEL (2000, p. IV)

Porém, para que esse processo ocorra, o material potencialmente significativo precisa ter sentido para o estudante, como afirma Ausubel (2000, p. 1) "A aprendizagem significativa não é sinónimo de aprendizagem de material significativo.”. Tudo que é apresentado ao sujeito que está no processo de apropriação, o que Ausubel chama de potencialmente significativo, está relacionado com o que o individuo já conhece. Cabal para que alcance os subsunçores que os alunos possuem, e nesta secção será abordada as partes da teoria do psicólogo David Ausubel.

Sobre o processo de construção do conhecimento, seguindo os princípios da aprendizagem significativa. Valadares e Moreira (2009, p. 15). apontam que “[...] a estrutura cognitiva complexa de cada ser humano tem importância decisiva na construção do seu próprio conhecimento". Na teoria de Ausubel a estrutura cognitiva de cada pessoa é levada consideração, uma vez que são através das estruturas cognitivas, conhecidas como subsunçores ou ideias prévias, que os novos conhecimentos se ancoram.

Sacristán e Gomez (1998, p. 39). definem que "Cada indivíduo capta a significação do material novo em função das peculiaridades historicamente construídas de sua estrutura cognitiva.”. Pelo fato de a significação só acontece devido às experiências e conhecimentos anteriores possuídos pelo sujeito, o material que se pretende ensinar possui uma característica específica que é a potencialidade de ser significativo.

Nesse aspecto, Sacristán e Gomez (1998, p. 39). afirmam que “A potencialidade significativa do material se encontra subordinada em cada indivíduo as características de sua bagagem cognitiva.". Essa é uma das condições mais importantes para que o aprendizado seja realmente significativo. Porém, não é sempre que o aprendiz possui subsuçores que possam ancorar os novos conhecimentos e, quando isso ocorre, uma nova forma de aprendizado acontece: a aprendizagem mecânica. Moreira e Masini (1982, p. 8-9). asseguram "Ausubel 
define aprendizagem mecânica (role learning) como sendo a aprendizagem de novas informações com pouca ou nenhuma associação com conceitos relevantes existentes na estrutura cognitiva.”. Essa falta de associação com os conceitos relevantes, pode estar revelando que o estudante não possui os subsunçores necessários para ancorar os novos conhecimentos.

Essas são características que consideram um aprendiz que se apresenta disposto a aprender ou possui interesse. Entretanto, quando essa não é a condição do estudante ou o material apresenta alguma falha significativa, o aprendizado não ocorre. Sobre esse aspecto Moreira e Masini (1982, p. 14). apontam como condição para o aprendizado significativo “[...] se a intenção do aprendiz é, simplesmente, a de memorizá-lo arbitrária e literalmente, tanto o processo de aprendizagem como seus produtos serão mecânicos ou sem significado.”. E como mencionado anteriormente, mesmo que o aprendiz apresente disposição para aprender e possui subsunçores a respeito do tema, se o material não for significativo, o aprendizado será mecânico.

Com relação ao período em que o aluno ingressa no âmbito escolar, o processo de aquisição e retenção do conhecimento também é abordado por Moreira e Masini (1982, p. 36). que "Começando com a entrada da criança na escola, uma proporção crescente de seus conceitos é adquirida por definição ou uso no contexto.”. Essa informação é importante pois durante esse período em que o aluno não é capaz de construir sozinho os seus conceitos, a partir de suas próprias ideias ele adquire o conceito pronto.

É nesse momento que o professor precisa fornecer um conceito significativo ao aluno, porque são nos primeiros anos escolares que se formam as bases futuramente necessárias para que ideias complexas sejam exploradas. Portanto, o professor precisa ter o cuidado, durante esse processo de construção dos primeiros conceitos que servirão de subsunçores mais adiante, para que esses sejam significativos.

Sendo eles significativos quando o estudante alcançar o período em que irá formular seus próprios conceitos a partir dos que já possui, e esses sejam amplos o bastante para fornecer suporte à novas ideias. E confirmando essas afirmações Moreira e Masini (1982, p 36). esclarecem que

Somente próximo à adolescência é que conceitos não-espontâneos se manifestam por meio de significado categórico generalizado. Antes dessa época, ela é ainda um pouco particularizada e intuitiva devido a sua dependência em apoios empírico-concretos durante a aquisição de conceitos. 
Como apontado por Moreira e Masini, o aluno tem uma dependência para que consiga adquirir os primeiros conceitos. Durante esse processo, o professor deve se certificar de que o processo de aquisição seja significativo. Para que no futuro o aluno tenha mais facilidade de aquisição de novos conhecimentos.

\section{Espacialidade Significativa: Uma Correlação Entre As Teorias No Âmbito Da Geografia Escolar}

Estudar e entender a terra é isso que a ciência geográfica propõe analisar, compreendendo as relações que os homens desenvolvem sobre ela e as relações que ocorrem no próprio meio. De acordo com Selbach (2010, p. 37)

Por ser uma ciência de paisagens e por despertar a visão interligada entre o homem e seu mundo, a geografia é um instrumento formidável para que possamos nos conhecer e nos compreender melhor, perceber toda a dimensão do espaço e do tempo, onde estamos e para onde caminhamos, descobrir as populações e suas múltiplas relações com o ambiente.

O Ensino de Geografia permite ao aluno ampliar suas percepções sobre o lugar onde ele vive e as relações que se desenvolvem todos os dias ao seu redor, além de favorecer um conhecimento mais amplo sobre o ambiente. Podendo assim compreender melhor o seu papel na sociedade. Por isso a importância da alfabetização cartográfica nos primeiros anos da escola. Selbach (2010, p. 40) destaca a importância do professor que está engajado com o aprendizado de seus alunos

Um professor de geografia verdadeiramente ensina quando ajuda seu aluno a aprender e, portanto, a se transformar, e também quando permite que seus alunos transformem informações em conhecimento. Considerando, pois, esse trabalho do professor, cabe destacar que toda aula de geografia deve apresentar sempre uma "ferramenta" que ajude o aluno em sua aprendizagem.

O professor que ensina tendo como base a aprendizagem significativa, estará preocupado em que seu aluno consiga perceber os valores que o assunto possui, e dentro da Cartografia, permitirá uma reconstrução e entendimento geográfico de seus espaços de vivências. E a ferramenta a ser destacada por Selbach, nada mais é que estratégias metodológicas para que o professor consiga alcançar o maior número de alunos de maneira significante.

Na intenção de apresentar as possibilidades entre Ausubel e Gardner, os conceitos de espaço e lugar também são importantes. O autor Yi-fu Tuan contribuiu com a abordagem desses dois conceitos na perspectiva das crianças. Porém, para o presente trabalho essa perspectiva 
será abordada no âmbito escolar. Tuan (1983, p. 35) afirma que "O horizonte geográfico da criança se expande à medida que ela cresce, mas não necessariamente passo a passo em direção à escala maior.". Portanto, é preciso que o professor leve em consideração o processo em que o Aluno irá ampliar sua visão de mundo e explorar as possibilidades que essa expansão apresentará.

Tuan (1983, p. 35) apresenta quais os primeiros interesses geográficos que os alunos podem ter durante seu desenvolvimento: "Seu interesse e conhecimento se fixam primeiro na pequena comunidade local, depois na cidade, saltando para o bairro; e da cidade de seu interesse pode pular para nação e para lugares estrangeiros, saltando a região.”. Como apontado por Tuan, os estudantes vão demonstrando interesses cada vez mais distantes do seu lugar de convivência. Em todos os estágios de expansão, o professor tem a possibilidade de explorar os conhecimentos do aluno, bem como enriquecer os conhecimentos. Contribuindo com essa discussão Callai (2005, p. 231) afirma que:

É preciso que haja concepções teórico-metodológicas capazes de permitir o reconhecimento do saber do outro, a capacidade de ler o mundo da vida e reconhecer a sua dinamicidade, superando o que está posto como verdade absoluta. É preciso trabalhar com a possibilidade de encontrar formas de compreender o mundo, produzindo um conhecimento que é legítimo.

Callai (2005) comenta que é preciso haver o reconhecimento do saber do outro, essa capacidade é trabalhada por Ausubel. O professor, atuando de forma significativa, precisa conhecer o que seu aluno já sabe sobre o tema. A apresentação do conteúdo requer do professor a capacidade de pensar estratégias metodológicas que alcancem o maior número de alunos de modo que elas sejam repletas de significados. Este autor também argumenta sobre a capacidade de ler o mundo sob o olhar da teoria de Gardner, propondo estimular a inteligência espacial. A fim de que esse estudante reconheça o lugar onde se encontra, e com base nessa capacidade, consiga reconhecer as especificidades do espaço. Retomando a discussão da alfabetização Cartográfica Callai (2005, p. 232)

Como realizar a leitura da palavra por meio da leitura do mundo? E como fazer a leitura do mundo por meio da leitura da palavra? Esse pode ser o desafio para pensar um aprendizado da alfabetização que seja significativo. Partindo do fato de que a gente lê o mundo ainda muito antes de ler a palavra, a principal questão é exercitar a prática de fazer a leitura do mundo. E pode-se dizer que isso nasce com a criança.

"Como realizar a leitura da palavra por meio da leitura do mundo? E como fazer a leitura do mundo por meio da leitura da palavra". Essas duas frases de Callai são um dos pontos em 
que as possibilidades de atuação com Ausubel e Gardner se encontram. Na teoria de Ausubel no auxílio da leitura do mundo e Gardner com a inteligência espacial, trazendo os significados vividos pelos alunos, como subsunçores para a leitura da palavra.

O professor almeja que seu aluno alcance o que Callai (2005, p. 235) destaca "Do ponto de vista da Geografia, esta é a perspectiva para se estudar o espaço: olhando em volta, percebendo o que existe, sabendo analisar as paisagens como o momento instantâneo de uma história que vai acontecendo.”. Essa visão está carregada de sentidos, que por diversos motivos o aluno pode não perceber, que a aprendizagem significativa pode apresentar, e o que pode dar suporte a esse processo é fazer uso da inteligência espacial.

O Ensino de Geografia tem como responsabilidade teórica de possibizar ao aluno a leitura do mundo e de sua realidade, a partir de aportes teóricos e metodológicos da Ciência, que fornecem subsídios ao professor em trabalhar conteúdos programáticos. A Cartografia constitui-se desses elementos, que atrelados a prática do professor, potencializa a aprendizagem, tornando-a significativa, contribuindo com essa perspectiva da leitura e atribuição de valores ao mundo.

\section{Considerações Finais}

Os primeiros anos escolares são fundamentais na construção dos conhecimentos básicos no Ensino de Geografia. Dentre eles a alfabetização Cartográfica merece destaque, pois proporciona o desenvolvimento de um raciocínio geográfico, reconhecimento do lugar, e a capacidade de abstração da representação cartográfica como uma ilustração da realidade. Á vista disso, este trabalho teve o intuito de apresentar a possibilidade de uma correlação entre a teoria das múltiplas inteligências de Gardner e a teoria da Aprendizagem Significativa de Ausubel. Em uma abordagem cujo foco pautava-se na Cartografia Escolar, tendo em vista que a linguagem cartográfica é elemento chave à Geografia, e retorna ao ensino como meio estruturante de conceitos na apreensão e percepção das especificidades da Ciência.

De acordo explicitado, a teoria de David Ausubel tem como objetivo uma atuação em que o professor primeiro considere os conhecimentos prévios (subsunçores) que o aluno possui a respeito do que se propõe ensinar, conhecido como ancoras servindo para fixação e assimilação de novos saberes. As propostas teóricas de Gardner são concebidas na interpretação de múltiplas inteligências, sendo o conjunto de habilidades que um indviduo possui e sua capacidade de resolução de problemas. Entre elas detaca-se a inteligência espacial, que 
corresponde a relação do sujeito com o espaço que o cerca, partindo de um referencial geográfico.

Foi possível perceber que a teoria do aprendizado significativo, tem a possibilidade de alcançar os alunos, proporcionando a eles multiplicas interpretações do mundo que estão inseridos e que possivelmente não percebam. A teoria de Gardner pode tanto atuar como ferramenta ativa na elaboração de modelos mentais em que o estudante consiga manipular, e como suporte para possibizar a capacidade de localização no espaço. Consequentemente, com a Aprendizagem Significativa, o estudante conseguirá atribuir novos valores aos lugares de sua convivência, o que poderá garantir uma maior facilidade de aprendizado de ideias complexas futuramente.

A Cartografia permite ao professor, a busca pelo desenvolvimento de uma inteligência espacial nos alunos. Embora que de forma indireta, ao trabalhar com mapas, globos e cartogramas, o docente explora a curiosidade, a percepção, a formação abstrata de lugares e a estruturação mental de formas e símbolos próprios.

Portanto, a espacialidade significativa é a junção entre as proposições teóricas apresentadas de Howard Gardner e David Ausubel. Seu uso permite ao aluno uma releitura dos conteúdos factuais, em uma abordagem empírica e experienciada, e que quando atreladas a estratégias metodológicas do professor, tornam a aprendizagem significativa. E essas, no futuro, serão âncoras aos conteúdos geográficos, em diferentes graus de complexidade, podendo facilitar a aprendizagem, uma vez que a base sólida contruida servirá de aporte ao processo evolutivo do conhecimento.

\section{Referências}

ALMEIDA, R. D. Cartografia escolar. 2. ed. São Paulo: Editora Contexto, 2010.

ANTUNES, C. Inteliências Múltiplas e seus Jogos: inteligência espacial. Petrópolis: Vozes, 2009.

BEZ, L. Sobre a inteligência espacial no ensino de geografia: notas para discussão. Revista de Geografia (UFPE), Pernambuco, v. 28, n. 3, p.58-67, 2011.

CARVALHO, H. A aplicação da Teoria de Inteligências Múltiplas de Howard Gardner no ensino de Geografia. 2018. 77 f. Relatório (Mestrado) - Curso de Mestrado em Ensino de Geografia no $3^{\circ}$ ciclo do Ensino Básico e no Ensino Secundário, Faculdade de Letras da Universidade do Porto, Porto, 2018.

CLAVAL, P. Epistemologia da Geografia. 2. ed. Florianópolis: Editora da Ufsc, 2014. 
GARDNER, H. et al. Inteligências múltiplas ao redor do mundo. Porto Alegre: Artmed, 2010.

GOMES, P. C. C. Quadros Geográficos: uma forma de ver, uma forma de pensar. Rio de Janeiro: Bertrand Brasil, 2017.

GARDNER, H. Estruturas da Mente: a teoria das Inteligências Mútiplas. Porto Alegre: Artes Médicas, 1994.

LUDWING, A. B; MARTINS, R. E. M. W. A geografia escolar nos anos iniciais: uma abordagem sobre os conhecimentos cartográficos no quinto ano. In: MARTINS, R. E. M. W. et al (Org.). Educação geográfica em movimento. Goiânia: C\&A Alfa Comunicação, 2019.

MENEGUETTE, A. A. C. Cartografia no século XXI: revisitando conceitos e definições. Revista Geografia e Pesquisa, Ourinhos, v. 6, n. 1, p.6-32, 2012.

MOREIRA, M; MASINI, E. F. S. Aprendizagem Significativa: a teoria de David Ausubel.São Paulo. Moraes, 1982.

NASCIMENTO, E; LUDWIG, A. B. A educação cartográfica no ensino-aprendizagem de Geografia: reflexões e experiências. Geografia Ensino \& Pesquisa, Santa Maria, v. 19, n. 3, p.29-42, 2015.

SACRISTÁN, J. G.; GÓMEZ, A. L. P. Compreender e transformar o ensino. 4 ed. Porto SANTOS, F; FECHINE, J. A. L. A cartografia escolar e sua importância para o ensino de Geografia. Caderno de Geografia, [s.1.], v. 27, n. 50, p.500-515, 3 ago. 2017.

SCHÄFFER, N. O. et al. Um globo em suas mãos: práticas para a sala de aula. 3. ed. Porto Alegre: Penso, 2011.

SMOLE, K. C. S. Múltiplas Inteligências na Prática Escolar. Brasília: Ministério da Educação, Secretaria de Educação a Distância, 1999. P. 80; 16 cm. - [Cadernos da TV Escola. Inteligências Múltiplas, ISSN 1517-2341 n.1)

SELBACH, S. Geografia e Didática. Petrópolis: Vozes, 2010.

TUAN, Yi-fu. Espaço e lugar: a perspectiva da experiência. Tradução: Lívia de Oliveira. São Paulo. Difel, 1983.

VALADARES, J. A.; MOREIRA, M. A. A teoria da aprendizagem significativa: sua fundamentação e implementação. Coimbra: Edições Almedina, 2009. 